\title{
Immunohistochemical staining of lipid droplets with adipophilin in paraffin-embedded glioma tissue identifies an association between lipid droplets and tumour grade
}

\author{
Sarah Kohe ${ }^{1}$, Isabel Colmenero ${ }^{2}$ Carmel McConville ${ }^{1}$ and Andrew Peet ${ }^{1,3^{*}}$ \\ *Correspondence: a.peet@bham.ac.uk

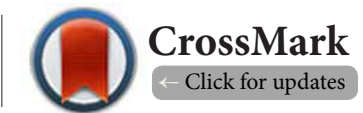

'Institute of Cancer and Genomic Sciences, University of Birmingham, Vincent Drive, Birmingham, B15 2TT, UK. 2Department of Histopathology, Birmingham Children's Hospital, Steelhouse Lane, Birmingham, B4 6NH, UK. ${ }^{3}$ Department of Oncology, Birmingham Children's Hospital, Steelhouse Lane, Birmingham, B4 6NH, UK.

\begin{abstract}
Background: Cytoplasmic lipid droplets are important in cancer metabolism and a clear relationship has been established between their accumulation and increased tumour grade in glioma. The development of the novel immunohistochemical marker adipophilin has proven to be a useful method of detecting lipid droplets in paraffin embedded tissue from many diseases. Our aim was to assess the distribution of adipophilin stained lipid droplets in paraffin embedded glioma tissue and to evaluate whether it is a useful indicator of lipid droplets in brain tumours.

Methods: Immunohistochemical staining for adipophilin was undertaken in a tissue microarray containing 65 paraffin embedded gliomas of varying grade. The number of tumour cells containing adipophilin positive lipid droplets was then quantified and statistically analysed.

Results: We found a statistically significant accumulation of lipid droplets in high grade glioblastoma compared to low grade astrocytomas when we quantified the percentage of tumour cells containing adipophilin-positive lipid droplets $(\mathrm{p}<0.001)$. A significant positive correlation $(r s=0.83)$ was detected between increasing tumour grade and the percentage of tumour cells containing lipid droplets, $p=0.0001$.

Conclusions: We have determined that adipophilin is a useful immunohistochemical marker of lipid droplets in brain tumours. The ability to detect lipid droplets within paraffin embedded gliomas will greatly facilitate the evaluation of this tumour characteristic which is related to grade and prognosis.
\end{abstract}

Keywords: Adipophilin, lipid droplets, glioblastoma, astrocytoma, immunohistochemistry, tumour metabolism, glioma

\section{Introduction}

Cytoplasmic lipid droplets are increasingly regarded as an important cellular component in both normal tissue [1] and in disease. Recent evidence suggests that the intracellular accumulation of lipid droplets is increased in a diverse range of diseases $[2,3]$. Once thought to be a storage compartment for neutral lipids, these organelles are now thought to be an important regulator of metabolic function and cell signalling [2-5].

The importance of lipid droplets in cancer metabolism is gaining clinical significance with many tumours including glioma found to have altered lipid profiles that change with grade and in response to treatment $[3,6,7]$. Lipid accumulation has been detected in high grade gliomas using ex-vivo nuclear magnetic resonance (NMR) techniques and evidence from electron microscopy and fluorescent labelling with Nile Red has determined that cytoplasmic lipid droplets are the major contributor to this lipid $[\mathbf{8 , 9 ]}$. In addition in-vivo magnetic resonance spectroscopy studies of both paediatric and adult brain tumours have reported increased lipids at diagnosis as a marker of poor prognostic outcome [10-12].

However, lipid droplets are not routinely assayed in tumour biopsies as histological detection methods were thought to be limited to frozen tissue. Whilst frozen tissue is used for histological diagnosis it is not as routine as the formalin fixed paraffin 
Kohe et al., Journal of Histology \& Histopathology 2017,

embedded (FFPE) tissue that nearly all diagnostic pathology is performed on. Recent advances have discovered a specific immunohistochemical marker localised to lipid droplets that can be carried out in FFPE tissue called adipocyte differentiation related protein (ADRP) or adipophilin [13]. The sub-cellular immunohistochemical expression of adipophilin has been found to be a useful marker of lipid accumulation in both tumours and non-neoplastic disease [4,13-16].

As intracellular lipids are a marker of both prognosis and treatment response in brain tumours $[10,12,17]$, the ability to routinely detect lipid droplets in FFPE biopsies taken from tumours at diagnosis may allow their detection to be more readily translated into clinical practice. As such, we have investigated adipophilin expression using immunohistochemistry in a series of tissue microarrays (TMAs) containing glioma tissue of varying grade and tumour type. By undertaking this study we aim to evaluate whether adipophilin is a useful indicator of lipid droplets in brain tumours.

\section{Materials and methods}

We obtained quality controlled high density commercial FFPE brain tumour microarrays from US Biomax (Rockville, MD, USA). These contained 65 glioma cases of varying diagnoses and grade along with normal brain tissue and normal tissue from other regions as controls for antibody validation purposes (Table 1). Each case was represented by two $1.5 \mathrm{~mm}$ cores with high resolution interactive $\mathrm{H}$ \& $\mathrm{E}$ images available for each. All cases were evaluated by pathologists and cores were selected to contain representative tumour rather than necrosis.

To validate the adipophilin antibody prior to use, we stained test TMAs containing brain tumour and control tissue, along with a commercial neuroblastoma cell line (BE2M17) that was grown in our laboratory as previously described [18] and processed into a paraffin embedded cell block. Previous work has shown that this cell line contains many large lipid droplets [18]. Immunohistochemical staining for adipophilin (AP125, Progen, Germany) was undertaken at a 1:50 dilution overnight at $4^{\circ} \mathrm{C}$ following heat mediated antigen retrieval. A Dako Envision polymer labelling system (K4065, Dako UK Ltd) was used to visualise the antibody, with diaminobenzene as the chromagenic label, followed by counterstaining with haematoxylin. Appropriate positive and negative tissue controls were included in all runs.

Quantification of the percentage of tumour cells containing cytoplasmic positivity for adipophilin-stained lipid droplets was undertaken independently by two individuals including a pathologist (IC). Rare nuclear staining was also noted, however only cytoplasmic staining was considered positive in tumour cells. Only staining within tumour cells was quantified, any adipophilin positive macrophages were not scored. Where there was discordant scores between the two observers, the cases were reviewed and consensus agreed. Scores from each core were averaged to provide a single score for each case. Averages were then obtained across tumour type and grade with statistical comparisons between groups undertaken with ANOVA, followed by the Student's t-test for post hoc comparisons. Correlations were undertaken using Spearman's rank correlation test.

\section{Results}

Adipophilin stained lipid droplets were identified in similar distribution patterns in the BE2M17 FFPE cell lines as previously determined using Nile red [18], providing evidence that the adipophilin antibody is correctly labelling lipid droplets (Figure 1). Adipophilin staining of lipid droplets was detected

Table 1. Summary of patient characteristics.

\begin{tabular}{|c|c|c|c|c|c|c|c|c|c|}
\hline & \multicolumn{9}{|c|}{ Clinical Diagnosis and Histopathological Grade } \\
\hline & $\begin{array}{l}\text { Pilocytic } \\
\text { Astrocytoma }\end{array}$ & Astrocytoma & $\begin{array}{l}\text { Anaplastic } \\
\text { Astocytoma }\end{array}$ & $\begin{array}{l}\text { Glioblastoma } \\
\text { (GBM) }\end{array}$ & $\begin{array}{l}\text { Oligo- } \\
\text { dendro- } \\
\text { glioma }\end{array}$ & $\begin{array}{l}\text { Anaplastic } \\
\text { Oligodendro- } \\
\text { glioma }\end{array}$ & $\begin{array}{l}\text { Giant } \\
\text { Cell } \\
\text { GBM }\end{array}$ & $\begin{array}{l}\text { Cancer } \\
\text { Adjacent } \\
\text { Normal } \\
\text { Brain^ }\end{array}$ & $\begin{array}{l}\text { Normal } \\
\text { Brain }\end{array}$ \\
\hline Tumour Grade ${ }^{+}$ & 1 & 2 & 3 & 4 & $1-2$ & - & 4 & normal & normal \\
\hline $\begin{array}{l}\text { Number of cases } \\
\text { stained }(n=80)\end{array}$ & 6 & 21 & 15 & 15 & 2 & 3 & 3 & 5 & 10 \\
\hline $\begin{array}{l}\text { Mean age of } \\
\text { patient group } \pm \\
\text { SD (years) }\end{array}$ & $39.83 \pm 16.33$ & $41.57 \pm 17.01$ & $44.85 \pm 16.09$ & $41.92 \pm 17.65$ & $49 \pm 8.89$ & $38.33 \pm 19.42$ & $31 \pm 13.52$ & $45 \pm 15.28$ & $35.6 \pm 11.10$ \\
\hline $\begin{array}{l}\text { Number of } \\
\text { cases containing } \\
\text { adipophilin- } \\
\text { positive tumour } \\
\text { cells }\end{array}$ & $3 / 6$ & $11 / 21$ & $11 / 15$ & $14 / 15$ & $2 / 3$ & $3 / 3$ & $3 / 3$ & $0 / 5$ & $3 / 10^{*}$ \\
\hline
\end{tabular}

+According to WHO classification criteria

${ }^{\wedge}$ Normal brain tissue taken from a non-involved region immediately adjacent to tumour

*staining restricted to neurons. The significance of this is unknown.

SD: Standard deviation 

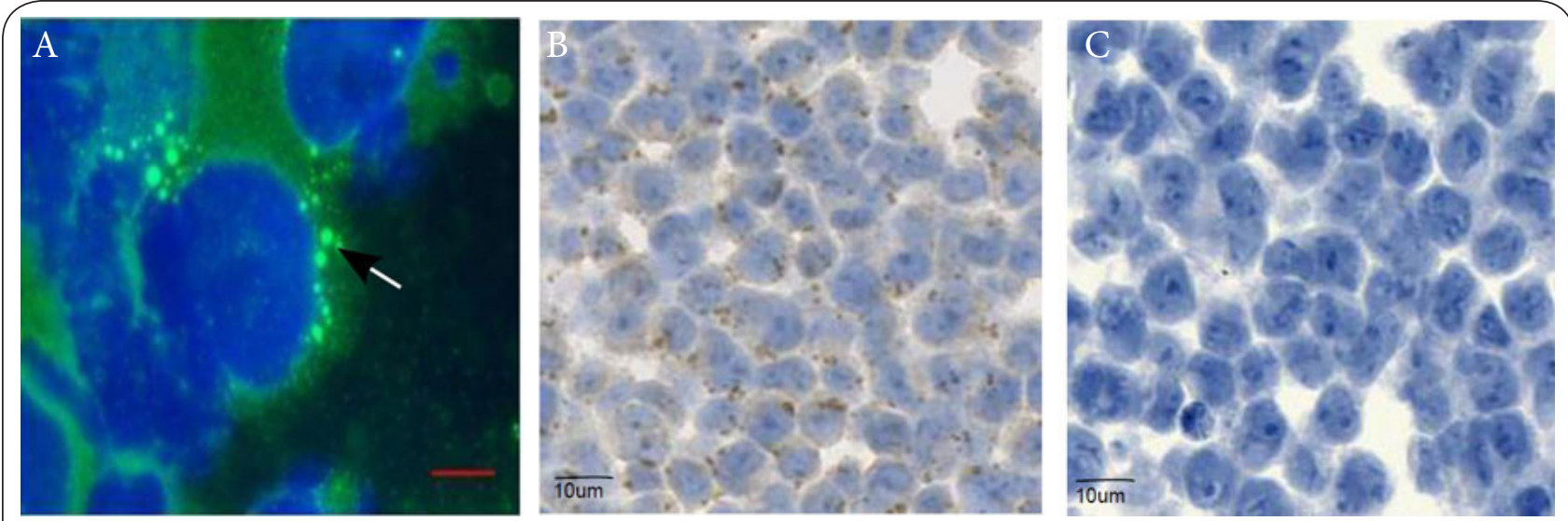

Figure 1. (A) Cytoplasmic lipid droplets fluorescently stained with Nile red in the fresh-fixed BE2M17 cell line (the arrow is indicating the stained lipid droplets in green, the nucleus has been co-labelled with DAPI in blue). (B) Immunohistochemical staining of adipophilin positive cytoplasmic lipid droplets in the paraffin-embedded cell line, BE2M17 (counterstained with haematoxylin). (C) Negative control with primary antibody omitted showing no adipophilin staining in BE2M17.

in $75 \%$ of all glioma cases analysed. This ranged from cases with very few tumour cells being stained $(<5 \%)$ to cases with very high numbers of positive tumour cells $(>90 \%)$. The mean percentage ( \pm standard error) of tumour cells expressing adipophilin positive lipid droplets in grade four glioblastoma was $56.19 \pm 5.69 \%$ (with a range from $30-93 \%$ ) which is significantly higher than in grade one and two astrocytoma, $p<0.0001$, (Figure 2). The mean percentage for grades one and two astrocytoma respectively, was $3.21 \pm 2.02 \%$ (with a range from $0-11 \%$ ), and $5.64 \pm 1.58$ (with a range from $0-26 \%$ ). Grade three astrocytoma had significantly less adipophilin positive cells ( $19 \pm 2.46 \%$, range from $0-35 \%$ ) than grade four

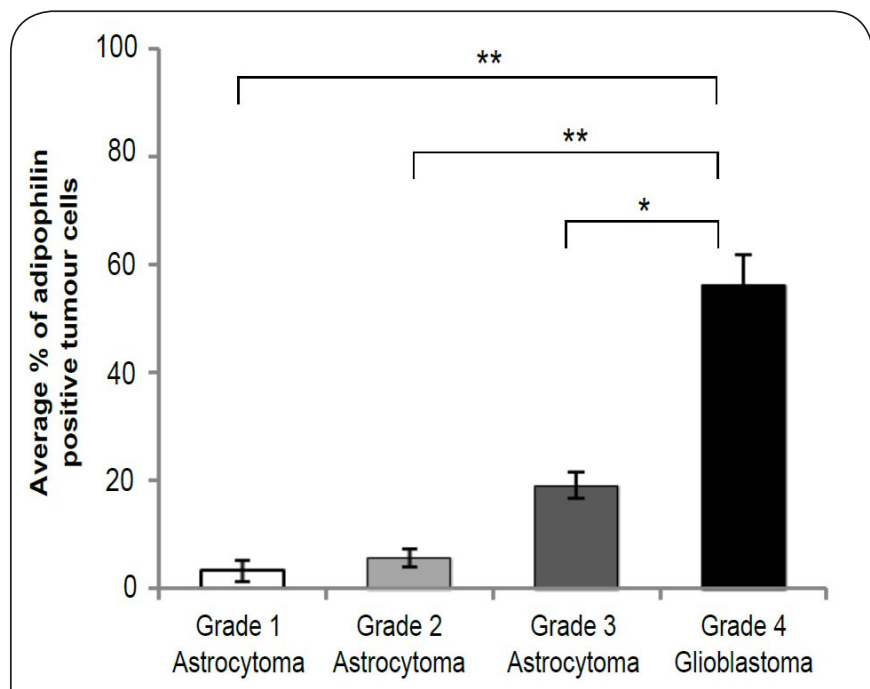

Figure 2. The immunohistochemical staining pattern of adipophilin in brain tumours. The average percentage of tumour cells containing adipophilin positive cytoplasmic lipid droplets in brain tumours of different grade (mean \pm standard error). Giant cell glioblastoma \& oligodendroglioma cases were not included in this analysis due to small sample numbers. glioblastoma ( $p=0.01$ ) but significantly more than grades one $(p=0.001)$ and two, $(p=0.04)$. A statistically significant correlation was detected between tumour grade and the percentage of tumour cells containing lipid droplets, $r s=0.83, p<0.0001$.

Strong positive expression was largely limited to cases of high grade glioblastoma, whilst weak positive staining was predominant in low grade pilocytic astrocytoma (Figure 3). There was also an increase in lipid droplets in high grade anaplastic oligodendroglioma (14.16 \pm 2.57$)$ compared to low grade oligodendrogliomas $(3.33 \pm 2.04)$ although case numbers were too small for formal statistical comparisons. Similar values of adipophilin positive tumour cells were found in the anaplastic astrocytomas and anaplastic oligodendrogliomas, with no statistically significantly difference between the tumour types. Cancer adjacent normal tumour cases were negative for adipophilin expressing cells, however, occasional cytoplasmic and nuclear adipophilin positivity (not counted during scoring) was found within neurons of normal brain. The scores for the two individual cores were within $5 \%$ of each other for the majority of cases (and less than 10\% for all cases) suggesting that adipophilin expression can be reliably detected within a tissue microarray according to established standards $[19,20]$.

\section{Discussion}

We have evaluated a series of brain tumours of varying grade for the expression of the lipid droplet marker adipophilin. To our knowledge this is the first study to examine lipid droplets in FFPE histological sections from gliomas of varying grade using an immunohistochemical marker. We have identified a significant increase in the percentage of tumour cells expressing adipophilin labelled lipid droplets in high grade tumours, suggesting that there is a relationship between the accumulation of lipid droplets and increasing tumour grade. A similar finding has been reported in Burkitt lymphoma 

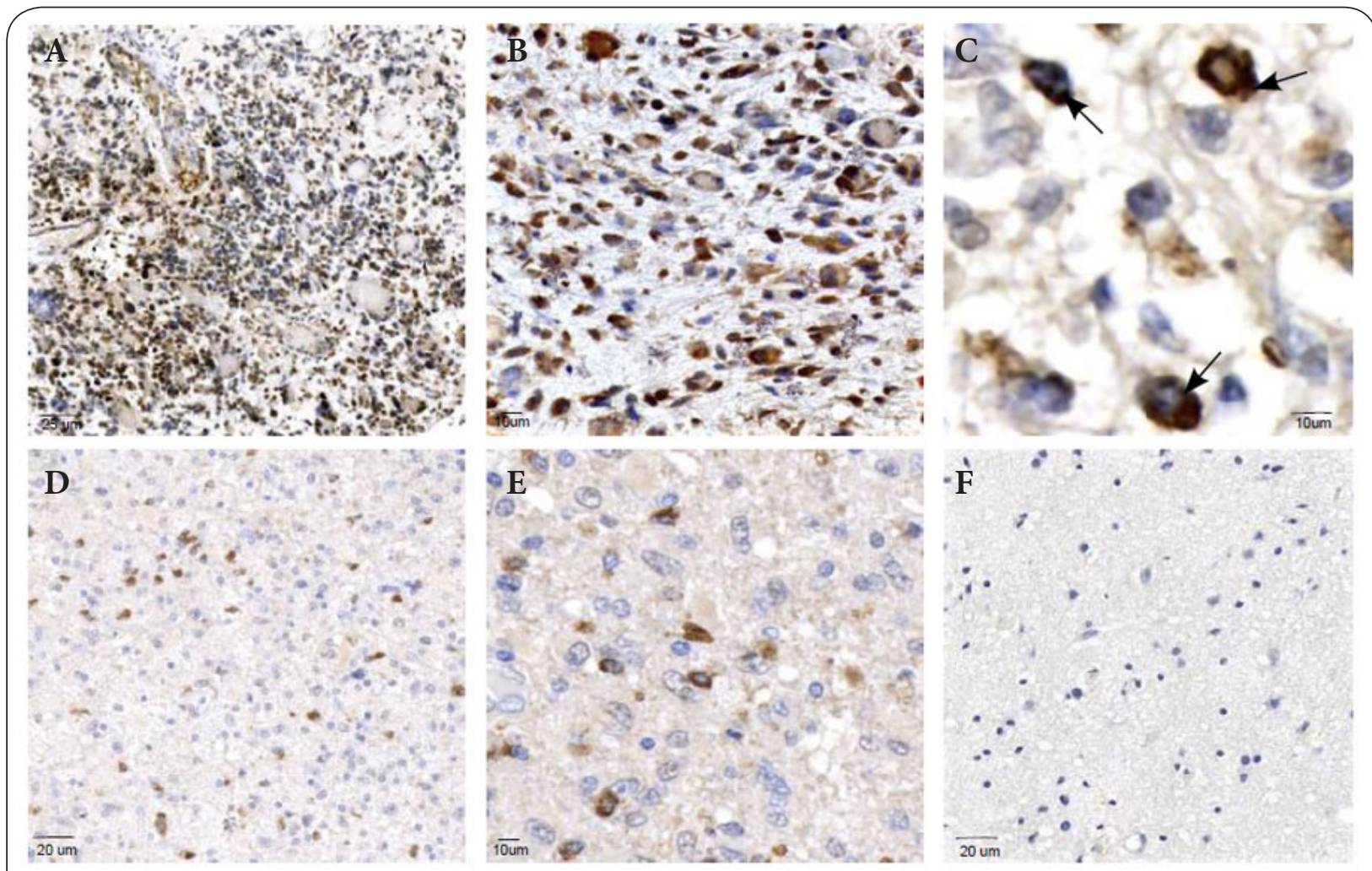

Figure 3. (A-C) Immunohistochemically stained adipophilin positive lipid droplets in tumour cells from a grade 4 glioblastoma (the arrow in $\mathrm{C}$ indicates the cytoplasmic distribution of the labelled lipid droplets). This strong widespread staining of tumour cells was largely restricted to grade four tumours. (D-E) Adipophilin positive tumour cells from a low grade astrocytoma. This sparse, less intense staining was largely typical of low grade tumours. (F) Low grade astrocytoma containing no adipophilin positive lipid droplets.

where adipophilin was shown to be a sensitive marker of lipid accumulation in high grade cases, and that it may be useful diagnostic discriminator in otherwise difficult cases [15]. As lipids are a marker of poor prognosis in gliomas [10-12] the ability to detect them in diagnostic biopsies is likely to be of clinical relevance. Interestingly, there were fewer adipophilin positive tumour cells in all three cases of giant cell glioblastoma when compared to grade four glioblastoma. As the giant cell variant is commonly regarded as less aggressive [17], this provides further support for the relationship between high lipid and worse prognosis. A similar trend was noted in the low grade oligodendrogliomas when compared to the anaplastic oligodendrogliomas, however these still had far fewer lipid droplet containing tumour cells than grade four glioblastomas. An exception to the relationship between grade and lipid in brain tumours may be grade two pleomorphic xanthoastrocytomas (PXA). These often contain cytoplasmic lipids with a generally favourable prognosis $[\mathbf{2 1}, \mathbf{2 2}]$. However as this is a rare variant, usually restricted to childhood, it was not included in our series from which only tumours from adults were analysed.

High grade glioblastoma in particular is known to be a heterogeneous tumour. Hence it is possible that analysis of a limited number of cores from each case within a tissue microarray may not accurately represent the entire tumour. However, our analysis found that the adipophilin scoring in two cores taken from different regions in each case was very consistent. Research using different markers in glioma tissue microarrays reported that whilst in some instances immunohistological scoring from single cores may not reflect the whole tumour section on an individual case basis, that when considered across a series of tumours, scores were not significantly different between microarrays and whole sections $[\mathbf{2 3}, \mathbf{2 4}]$. This suggests that like other tumour types, accurate histological measures can still be undertaken in a microarray despite tumour heterogeneity $[23,25]$.

There is a well known association between lipids and necrosis in many tumour types [6]. The tissue cores selected for this study were taken from tumour only rather than the necrotic core demonstrating that lipid is also detected within the cytoplasm of tumour cells and is not only a marker of necrosis within brain tumours. Strong positive expression of adipophilin was generally only found in grade four tumours suggesting not only that a greater number of tumour cells contain lipid droplets, but also that there is a greater number and/or an increase in size of these organelles within the cell. Previous 
Kohe et al., Journal of Histology \& Histopathology 2017,

work from our group has found that the size of lipid droplets can vary across several neural-derived tumour cell lines and that both size and composition can change in response to treatments that target metabolic pathways $[\mathbf{2 6 , 2 7 ]}$. Disruption of lipid metabolism in glioma has also been identified as a potential therapeutic target $[\mathbf{7 , 2 8}]$. As lipid accumulation appears to be an important indicator of increased metabolic state within high grade malignancies there is likely to be biological and diagnostic value to observing lipid droplets in biopsied brain tumours.

Cytoplasmic adipophilin positivity was detected within the neurons of normal brain in only three cases suggesting that there are few lipid droplets present in normal brain tissue. Nuclear lipid droplets were also detected within occasional neurons. Although most studies have focused on cytoplasmic lipid droplets $[3,4]$, recent evidence using confocal and electron microscopy in cultured hepatocytes suggests that neutral lipids within the nucleus also form into spherical lipid droplets of unique composition and size and that these may be involved with nuclear lipid homeostasis $[29,30]$. Alternatively it has also been proposed that cytoplasmic lipid droplets may be mistaken as nuclear in instances where they have a close association with the nuclear envelope [31]. Although recent evidence in Alzheimer's and Huntington's disease has reported that cytoplasmic lipid droplets do occur in neurons in a disease state [32], it is unclear as to the significance of this finding within normal neurons in this study and this requires further investigation.

An important advantage of establishing adipophilin immunohistochemical staining in paraffin embedded gliomas is the ability to investigate lipids both retrospectively in archival glioma tissue as well as prospectively in future studies. As increased lipids have been shown to have prognostic value, it will be important to directly link the presence of lipid droplets to survival and outcome in glioma. Of additional clinical significance will be linking lipids to molecular prognostic markers such as IDH1 and ATRX mutations and MGMT promoter methylation, all of which are known to influence survival in glioma. Further studies are also required to investigate the relationship between adipophilin-stained lipid droplets and measures of in vivo and ex-vivo lipids from MR spectroscopy as well as their links to survival.

\section{Conclusions}

In summary, we have shown that adipophilin is a valuable marker of lipid droplet status in paraffin embedded glioma tissue and used the method to establish the relationship between the accumulation of cytoplasmic lipid droplets and increased tumour grade in these tumours. The availability of a robust method for determining lipid droplet status in paraffin embedded tissue will greatly facilitate the further evaluation of lipid droplets as a biomarker of grade and prognosis and its translation into routine clinical practice.

\section{Competing interests}

The authors declare that they have no competing interests.

Authors' contributions

\begin{tabular}{|l|c|c|c|c|}
\hline Authors' contributions & SK & IC & CC & AP \\
\hline Research concept and design & $\checkmark$ & -- & -- & $\checkmark$ \\
\hline Collection and/or assembly of data & $\checkmark$ & -- & -- & -- \\
\hline Data analysis and interpretation & $\checkmark$ & $\checkmark$ & -- & -- \\
\hline Writing the article & $\checkmark$ & -- & -- & -- \\
\hline Critical revision of the article & $\checkmark$ & $\checkmark$ & $\checkmark$ & $\checkmark$ \\
\hline Final approval of article & $\checkmark$ & $\checkmark$ & $\checkmark$ & $\checkmark$ \\
\hline Statistical analysis & $\checkmark$ & -- & -- & -- \\
\hline
\end{tabular}

Acknowledgement

This work was funded by the Andrew McCartney Trust for Brain Tumour Research. AP is funded by a research professorship from the National Institute of Health Research.

\section{Publication history}

EIC: Gaetano Giuseppe Magro, University of Catania, Italy. Received: 03-Sep-2016 Final Revised: 11-Apr-2017 Accepted: 29-Apr-2017 Published: 11-May-2017

\section{References}

1. Shaw CS, Sherlock M, Stewart PM and Wagenmakers AJ. Adipophilin distribution and colocalization with lipid droplets in skeletal muscle. Histochem Cell Biol. 2009; 131:575-81. | Article | PubMed

2. Martin $S$ and Parton RG. Lipid droplets: a unified view of a dynamic organelle. Nat Rev Mol Cell Biol. 2006; 7:373-8. | Article I PubMed

3. Santos CR and Schulze A. Lipid metabolism in cancer. FEBS J. 2012; 279:2610-23. | Article | PubMed

4. Straub BK, Gyoengyoesi B, Koenig M, Hashani M, Pawella LM, Herpel E, Mueller W, Macher-Goeppinger S, Heid H and Schirmacher P. Adipophilin/perilipin-2 as a lipid droplet-specific marker for metabolically active cells and diseases associated with metabolic dysregulation. Histopathology. 2013; 62:617-31. I Article I PubMed

5. Greenberg AS, Coleman RA, Kraemer FB, McManaman JL, Obin MS, Puri V, Yan QW, Miyoshi H and Mashek DG. The role of lipid droplets in metabolic disease in rodents and humans. J Clin Invest. 2011; 121:210210. | Article | PubMed Abstract | PubMed FullText

6. Delikatny EJ, Chawla S, Leung DJ and Poptani H. MR-visible lipids and the tumor microenvironment. NMR Biomed. 2011; 24:592-611. | Article | PubMed Abstract | PubMed FullText

7. Guo D, Bell EH and Chakravarti A. Lipid metabolism emerges as a promising target for malignant glioma therapy. CNS Oncol. 2013; 2:28999. | Article | PubMed Abstract | PubMed FullText

8. Opstad KS, Bell BA, Griffiths JR and Howe FA. An investigation of human brain tumour lipids by high-resolution magic angle spinning 1H MRS and histological analysis. NMR Biomed. 2008; 21:677-85. | Article | PubMed

9. Remy C, Fouilhe N, Barba I, Sam-Lai E, Lahrech H, Cucurella MG, Izquierdo M, Moreno A, Ziegler A, Massarelli R, Decorps M and Arus C. Evidence that mobile lipids detected in rat brain glioma by $1 \mathrm{H}$ nuclear magnetic resonance correspond to lipid droplets. Cancer Res. 1997; 57:407-14. | Article | PubMed

10. Wilson M, Cummins CL, Macpherson L, Sun Y, Natarajan K, Grundy RG, Arvanitis TN, Kauppinen RA and Peet AC. Magnetic resonance spectroscopy metabolite profiles predict survival in paediatric brain tumours. Eur J Cancer. 2013; 49:457-64. | Article | PubMed Abstract | PubMed FullText

11. Howe FA, Barton SJ, Cudlip SA, Stubbs M, Saunders DE, Murphy M, Wilkins P, Opstad KS, Doyle VL, McLean MA, Bell BA and Griffiths JR. Metabolic profiles of human brain tumors using quantitative in vivo $1 \mathbf{H}$ 
Kohe et al., Journal of Histology \& Histopathology 2017,

http://www.hoajonline.com/journals/pdf/2055-091X-4-4.pdf

magnetic resonance spectroscopy. Magn Reson Med. 2003; 49:223-32. Article I PubMed.

12. Li X, Jin H, Lu Y, Oh J, Chang S and Nelson SJ. Identification of MRI and $\mathbf{1 H}$ MRSI parameters that may predict survival for patients with malignant gliomas. NMR Biomed. 2004; 17:10-20. | Article | PubMed

13. Heid HW, Moll R, Schwetlick I, Rackwitz HR and Keenan TW. Adipophilin is a specific marker of lipid accumulation in diverse cell types and diseases. Cell Tissue Res. 1998; 294:309-21. | Article I PubMed

14. Ueo T, Yonemasu H, Yada N, Yano S, Ishida T, Urabe M, Takahashi K, Nagamatsu H, Narita R, Yao K, Daa T and Yokoyama S. White opaque substance represents an intracytoplasmic accumulation of lipid droplets: immunohistochemical and immunoelectron microscopic investigation of 26 cases. Dig Endosc. 2013; 25:147-55. | Article | PubMed

15. Ambrosio MR, Piccaluga PP, Ponzoni M, Rocca BJ, Malagnino V, Onorati M, De Falco G, Calbi V, Ogwang M, Naresh KN, Pileri SA, Doglioni C, Leoncini $L$ and Lazzi $S$. The alteration of lipid metabolism in Burkitt lymphoma identifies a novel marker: adipophilin. PLoS One. 2012; 7:e44315. | Article | PubMed Abstract | PubMed FullText

16. Muthusamy K, Halbert $G$ and Roberts F. Immunohistochemical staining for adipophilin, perilipin and TIP47. J Clin Pathol. 2006; 59:1166-70. | Article | PubMed Abstract | PubMed FullText

17. Kozak KR and Moody JS. Giant cell glioblastoma: a glioblastoma subtype with distinct epidemiology and superior prognosis. Neuro Oncol. 2009; 11:833-41. | Article | PubMed Abstract | PubMed FullText

18. Pan X, Wilson M, McConville C, Arvanitis TN, Kauppinen RA and Peet AC. The size of cytoplasmic lipid droplets varies between tumour cell lines of the nervous system: a 1H NMR spectroscopy study. MAGMA. 2012; 25:479-85. | Article | PubMed

19. Kyndi M, Sorensen FB, Knudsen H, Overgaard M, Nielsen HM, Andersen J and Overgaard J. Tissue microarrays compared with whole sections and biochemical analyses. A subgroup analysis of DBCG 82 b\&c. Acta Oncol. 2008; 47:591-9. | Article | PubMed

20. Rimm DL, Nielsen TO, Jewell SD, Rohrer DC, Broadwater G, Waldman F, Mitchell KA, Singh B, Tsongalis GJ, Frankel WL, Magliocco AM, Lara JF, Hsi ED, Bleiweiss IJ, Badve SS, Chen B, Ravdin PM, Schilsky RL, Thor $A$ and Berry DA. Cancer and Leukemia Group B Pathology Committee guidelines for tissue microarray construction representing multicenter prospective clinical trial tissues. J Clin Oncol. 2011; 29:2282-90. | Article | PubMed Abstract | PubMed FullText

21. van Roost D, Kristof R, Zentner J, Wolf HK and Schramm J. Clinical, radiological, and therapeutic features of pleomorphic xanthoastrocytoma: report of three patients and review of the literature. J Neurol Neurosurg Psychiatry. 1996; 60:690-2. | Article | PubMed Abstract | PubMed FullText

22. Hirose T, Giannini $C$ and Scheithauer BW. Ultrastructural features of pleomorphic xanthoastrocytoma: a comparative study with glioblastoma multiforme. Ultrastruct Pathol. 2001; 25:469-78. | Article I PubMed

23. Wang $\mathrm{H}$, Zhang $\mathrm{W}$ and Fuller GN. Tissue microarrays: applications in neuropathology research, diagnosis, and education. Brain Pathol. 2002; 12:95-107. | Article | PubMed

24. Chiesa-Vottero AG, Rybicki LA and Prayson RA. Comparison of proliferation indices in glioblastoma multiforme by whole tissue section vs tissue microarray. Am J Clin Pathol. 2003; 120:902-8. | Article | PubMed

25. Kallioniemi OP, Wagner U, Kononen J and Sauter G. Tissue microarray technology for high-throughput molecular profiling of cancer. Hum $\mathrm{Mol}$ Genet. 2001; 10:657-62. | Article I PubMed

26. Pan X, Wilson M, McConville C, Arvanitis TN, Griffin JL, Kauppinen RA and Peet AC. Increased unsaturation of lipids in cytoplasmic lipid droplets in DAOY cancer cells in response to cisplatin treatment. Metabolomics. 2013; 9:722-729. | Article | PubMed Abstract | PubMed FullText

27. Mirbahai L, Wilson M, Shaw CS, McConville C, Malcomson RD, Kauppinen
RA and Peet AC. Lipid biomarkers of glioma cell growth arrest and cell death detected by $1 \mathrm{H}$ magic angle spinning MRS. NMR Biomed. 2012; 25:1253-62. | Article | PubMed

28. Sun P, Xia S, Lal B, Shi X, Yang KS, Watkins PA and Laterra J. Lipid metabolism enzyme ACSVL3 supports glioblastoma stem cell maintenance and tumorigenicity. BMC Cancer. 2014; 14:401. | Article | PubMed Abstract | PubMed FullText

29. Layerenza JP, Gonzalez P, Garcia de Bravo MM, Polo MP, Sisti MS and Ves-Losada A. Nuclear lipid droplets: a novel nuclear domain. Biochim Biophys Acta. 2013; 1831:327-40. I Article I PubMed

30. Uzbekov R and Roingeard P. Nuclear lipid droplets identified by electron microscopy of serial sections. BMC Res Notes. 2013; 6:386. | Article | PubMed Abstract | PubMed FullText

31. Pol A, Gross SP and Parton RG. Review: biogenesis of the multifunctional lipid droplet: lipids, proteins, and sites. J Cell Biol. 2014; 204:635-46. | Article | PubMed Abstract | PubMed FullText

32. Welte MA. Expanding roles for lipid droplets. Curr Biol. 2015; 25:R47081. | Article | PubMed Abstract | PubMed FullText

\section{Citation:}

Kohe S, Colmenero I, McConville C and Peet A. Immunohistochemical staining of lipid droplets with adipophilin in paraffin-embedded glioma tissue identifies an association between lipid droplets and tumour grade. J Histol Histopathol. 2017; 4:4. http://dx.doi.org/10.7243/2055-091X-4-4 